\title{
Percutaneous transluminal coronary angioplasty of one vessel for refractory unstable angina pectoris: efficacy in single and multivessel disease
}

\author{
BIMLENDRA SHARMA, RICHARD P WYETH, GEORGE S KOLATH, \\ HORACIO J GIMENEZ, JOSEPH A FRANCIOSA
}

From the Cardiovascular Division, The University of Arkansas for Medical Sciences, Little Rock, Arkansas, USA

SUMMARY Forty patients with unstable angina refractory to medical treatment had one vessel percutaneous transluminal angioplasty to the most stenotic lesion in a major coronary artery. The procedure was successful in 35 patients, and the remaining five patients underwent emergency coronary artery bypass graft surgery. The initial success rate $(84 \%)$ for the 16 patients with single or the 19 patients with multivessel disease $(90 \%$ ) was similar. At early follow up (average nine days) $\stackrel{\rho}{\supset}$ all patients with successful angioplasty remained symptomatically improved; 10 patients $(83 \%) \vec{\bullet}$ with single and 10 patients $(63 \%)$ with multivessel disease had negative treadmill stress tests. Five $\infty$ of six cardiac events occurred within the intermediate (average 11 months) follow up period; two patients had recurrent refractory unstable angina, two had angioplasty for progression of disease in a vessel not previously treated by angioplasty, and one had bypass graft surgery. During late (average 26 months) follow up one patient had a non-fatal myocardial infarction while seven patients $(58 \%)$ with single vessel disease and nine patients $(75 \%)$ with multivessel disease had negative stress tests; 29 of 40 patients showed long term improvement.

Unstable angina pectoris can rapidly progress to myocardial infarction or death despite vigorous medical treatment. ${ }^{1-4}$ Thus patients with unstable angina are usually admitted to the coronary care unit and treated with multiple drugs including long and short acting nitrates, ${ }^{5} \beta$ blockers, ${ }^{6}$ antiplatelet agents, ${ }^{7}$ and calcium channel antagonists. ${ }^{89}$ Despite these measures some patients continue to experience angina and because they are at high risk for myocardial infarction and death ${ }^{10}$ they are considered for early coronary artery bypass surgery. Recent investigations have shown that like surgical treatment percutaneous transluminal coronary angioplasty may be effective in the treatment of unstable angina pectoris ${ }^{11-13}$ even in emergency situations in patients who do not respond to medical treatment. ${ }^{14}$ Most patients in these earlier studies had single vessel coronary artery disease. This is not a common angiographic finding in patients with unstable angina where the

Requests for reprints to Dr Bimlendra Sharma, Cardiac Catheterization Laboratory, University of Arkansas for Medical Sciences, 4301 West Markham, Mail Slot 532, Little Rock, AR 72205, USA.

Accepted for publication 8 September 1987 majority have multivessel disease. ${ }^{2}$ Consequently, the efficacy of percutaneous transluminal coronary angioplasty in patients with unstable angina that is refractory to maximal medical treatment and multivessel disease is not well defined.

We have evaluated the immediate and late symptomatic, functional, and angiographic state of patients after percutaneous transluminal coronary angioplasty of a single, critically stenotic, major artery for refractory unstable angina. Thus this study compares the results of complete angioplastic $\frac{T}{2}$ revascularisation in single vessel disease with those of incomplete angioplastic revascularisation in multi- $/$ vessel disease in patients with refractory unstable $N$ angina.

\section{Patients and methods}

PATIENTS

During a two year enrolment period 40 patients with refractory unstable angina entered this study. 0 Refractory unstable angina was defined as the persistence of anginal symptoms despite maximally tolerated combined $\beta$ adrenergic blockade, nitrates, antiplatelet treatment, and/or calcium antagonists 
when given for at least 48 hours.

Unstable refractory angina was subdivided as follows: (a) occurring at rest or with minimal effort; (b) of recent onset $(<1$ month and progressively increasing in frequency, duration, and/or severity); (c) occurring $<$ six weeks after myocardial infarction. ${ }^{15}$ Acute myocardial infarction was ruled out by serial creatine kinase measurements and electrocardiograms obtained over a minimum of 48 hours in the coronary care unit. No patient included in this study had congestive heart failure, cardiomyopathy, valve disease, or left ventricular aneurysm. No attempt was made to negotiate totally occluded vessels, left main lesions, or any lesion greater than $8 \mathrm{~mm}$ in length and these patients were excluded from the study.

The details of percutaneous transluminal coronary angioplasty, risks, benefits, and the possibility of emergency coronary artery bypass surgery were explained to each patient. Informed written consent was obtained from the patient and an immediate relative.

\section{PERCUTANEOUS TRANSLUMINAL CORONARY ANGIOPLASTY PROCEDURE}

Routine coronary angiography was performed by the standard Seldinger technique. The severity of coronary lesions was measured as the maximum percentage diameter narrowing in any standard radiographic view. Percutaneous transluminal coronary angioplasty was performed by the Grüntzig technique ${ }^{16}$ modified for use with a steerable system. In patients with one vessel disease, coronary angioplasty was performed if a stenosis of $\geqslant 70 \%$ was present. In multivessel disease, defined as $\geqslant 70 \%$ stenosis in two or more coronary arteries, a single percutaneous transluminal coronary angioplasty was performed to the most stenotic lesion within a major vessel. Just before angioplasty, patients received prophylactic sublingual glyceryl trinitrate $(0.3 \mathrm{mg})$ and intravenous heparin (10 000 IU) to prevent possible coronary spasm and thrombosis respectively. Balloon inflations were repeated to produce a satisfactory dilatation as determined by a reduction in the pressure gradient across the lesion and an improvement in angiographic appearance of the stenosis. Multiple projection coronary arteriography was performed to confirm the result. An angioplasty procedure was considered successful when it reduced the stenotic lesion to $\leqslant 50 \%$ and the transstenotic pressure gradient by $\geqslant 30 \mathrm{~mm} \mathrm{Hg}$.

For the first 24 hours after angioplasty, patients were monitored in the coronary care unit, where serial electrocardiograms were obtained and serial creatine kinase activity was measured as clinically indicated. For this first 24 hour period after angio- plasty, femoral sheaths were left in place and patients were treated with intravenous heparin. Antianginal treatment including intravenous glyceryl trinitrate was given during the initial 24 hours after angioplasty and then gradually tapered off.

\section{FOLLOW UP EVALUATION}

Successfully treated patients were followed at regular clinic visits. The severity of angina was graded according to the New York Heart Association classification. Patients were only followed until the following cardiac end points: recurrence of refractory unstable angina; percutaneous transluminal coronary angioplasty of a vessel other than the vessel originally dilated for relief of refractory unstable angina; myocardial infarction; and death. Patients who had percutaneous transluminal angioplasty for restenosis of the originally dilated vessel for other than refractory unstable angina remained in the study.

Treadmill stress tests with the standard Bruce protocol were performed within one month of angioplasty, and at three, six, and every six months after angioplasty. No patient was taking digitalis. All antianginal medications except vasodilators were stopped 24 hours before exercise testing. Vasodilators were withdrawn six hours, before the stress test. All 12 standard electrocardiographic leads were monitored throughout the test. A horizontal or downsloping ST segment depression of $0.1 \mathrm{mV}$ or more occurring $0.08 \mathrm{~s}$ after the $\mathrm{J}$ point during exercise was regarded as a positive test. Because many patients had numerous stress tests, results of the test done within the first 30 days, the most recent within one year, and the most recent done at least one year after angioplasty are reported.

In the event of recurrence of anginal symptoms or a positive treadmill stress test, patients were advised to undergo repeat coronary angiography, and if indicated repeat percutaneous transluminal coronary angioplasty was performed.

\section{TIMING OF FOLLOW UP EXAMINATIONS}

Follow up is divided into early (within one month of angioplasty), intermediate (one month to 12 months after angioplasty), and late ( $>12$ months after angioplasty).

\section{DATA ANALYSIS}

Data are expressed, when appropriate, as the mean (1 SD). We use the Statistical Analytical System on an IBM 4381 to test for intragroup significance by a paired $t$ test, proportions by either chi-square analysis or the Fisher exact test as appropriate, and morbidity by actuarial analysis. The term significant used within the text implies a p value $<0.05$. 


\section{Results}

PATIENT CHARACTERISTICS AND CORONARY ANGIOGRAPHIC FINDINGS

There were no significant differences between the characteristics of patients with single or multivessel disease (table 1). In patients with multivessel diseases, 19 had two vessel disease and two had significant disease within all three major coronary vessels.

IMMEDIATE RESULTS OF ANGIOPLASTY

One vessel percutaneous transluminal coronary angioplasty was initially successful in 35 (88\%) of 40 patients (table 2). Patients with single or multivessel disease had similar results. The initial success rate for angioplasty of lesions of either the left anterior descending or left circumflex coronary arteries was also similar in patients with single or multivessel disease. The initial success rate was lower in patients who had angioplasty of the right coronary artery and single vessel disease than in patients who had angioplasty of the right coronary artery and multivessel disease, but this difference was not statistically significant ( $p>0.37$ ). Furthermore, initial success rates for proximal $(87 \%)$, mid $(100 \%)$, and distal $(83 \%)$ lesions were not significantly different. In the 35 successfully treated patients, angioplasty reduced the mean (SD) stenosis from 84 (10)\% to $20(5) \%$ (p $<0.001)$ and the mean (SD) pressure gradient from 60 (18) $\mathrm{mm} \mathrm{Hg}$ to 12 (11) $\mathrm{mm} \mathrm{Hg}$ ( $\mathrm{p}<0.001$ ). Angioplasty failed in five patients who went to emergency coronary artery bypass graft surgery: three for impending myocardial infarction caused by vessel occlusion and two patients for recurrent $\stackrel{\overline{\mathcal{S}}}{+}$ coronary spasm.

EARLY FOLLOW UP (WITHIN ONE MONTH) Thirty five patients were asymptomatic during the $\triangle$ early follow up period and had no cardiac events (fig 1). Antianginal medications were stopped in $14 \overrightarrow{-}$ $(40 \%)$ before discharge while the remaining $21:$ patients were discharged while medication was $\vec{\omega}$ gradually stopped. Eighteen of these 35 patients were hypertensive and nine were discharged on $\beta$ blockers or calcium channel blockers. Treadmill stress tests 0 were performed by $28(80 \%)$ of 35 patients (table 3$)$. This test was negative in $20(71 \%)$ patients. Within the first month no patient had repeat angiography or angioplasty. Thus all 35 patients entered intermediate follow up.

INTERMEDIATE FOLLOW UP (MEAN 11 MONTHS) Twenty three $(66 \%)$ of these 35 patients remained symptom free, seven $(20 \%)$ had class II angina, and $\vec{\omega}$ five $(14 \%)$ had a cardiac event. Figure 1 compares $\infty$ symptoms in patients with single vessel disease and 0 those with multivessel disease. Of the 23 symptom free patients, six were taking no medications while the remaining 17 were taking $\beta$ blocker calcium channel blockers or both. Eleven of these 17 symptom free patients continued on these antihypertensives while the remaining six normotensive patients were taking small prophylactic doses of $\beta$ blockers or

Table 1 Clinical features in 40 patients

\begin{tabular}{|c|c|c|c|}
\hline Patient characteristics & $\begin{array}{l}S V D \\
\text { No }(\%)\end{array}$ & $\begin{array}{l}M V D \\
N o(\%)\end{array}$ & $\begin{array}{l}\text { Total } \\
\text { No }\left(0_{0}\right)\end{array}$ \\
\hline $\begin{array}{l}\text { Patients } \\
\text { Sex (male) } \\
\text { Average age (years (range)) } \\
\text { Previous myocardial infarction } \\
\text { Previous CABG } \\
\text { New onset of angina at rest } \\
\text { Crescendo angina } \\
\text { Angina within six weeks of AMI } \\
\text { Diabetes mellitus } \\
\text { Essential hypertension }\end{array}$ & $\begin{array}{l}19(48) \\
14(35) \\
55(31-82) \\
2(5) \\
1(3) \\
7(18) \\
11(28) \\
1(3) \\
1(3) \\
10(25)\end{array}$ & $\begin{array}{l}21(52) \\
14(35) \\
56(43-74) \\
6(15) \\
1(2) \\
5(12) \\
8(20) \\
8(20) \\
4(10) \\
8(20)\end{array}$ & $\begin{aligned} 40 & (100) \\
28 & (70) \\
56 & (31-82) \\
8 & (20) \\
2 & (5) \\
12 & (30) \\
19 & (48) \\
9 & (23) \\
5 & (13) \\
18 & (45)\end{aligned}$ \\
\hline
\end{tabular}

AMI, acute myocardial infarction; CABG, coronary artery bypass graft; MVD, multivessel disease; SVD, single vessel disease.

Table 2 Vessel in which percutaneous transluminal coronary angioplasty was attempted and immediate results

\begin{tabular}{|c|c|c|c|c|c|c|}
\hline & \multicolumn{2}{|l|}{$S V D$} & \multicolumn{2}{|l|}{$M V D$} & \multicolumn{2}{|l|}{ Total } \\
\hline & $\begin{array}{l}\text { Attempted } \\
\text { No }\end{array}$ & $\begin{array}{l}\text { Successful } \\
\text { No }(\%)\end{array}$ & $\begin{array}{l}\text { Attempted } \\
\text { No }\end{array}$ & $\begin{array}{l}\text { Successful } \\
\text { No }(\%)\end{array}$ & $\begin{array}{l}\text { Attempted } \\
\text { No }\end{array}$ & $\begin{array}{l}\text { Successful } \\
\text { No }(\%)\end{array}$ \\
\hline $\begin{array}{l}\text { LAD } \\
\text { LCX } \\
\text { RCA } \\
\text { CABG } \\
\text { Total }\end{array}$ & $\begin{array}{r}14 \\
1 \\
3 \\
1 \\
19\end{array}$ & $\begin{array}{c}12(86) \\
1 \\
2(67) \\
1 \\
16(84)\end{array}$ & $\begin{array}{r}10 \\
6 \\
5 \\
0 \\
21\end{array}$ & $\begin{array}{c}8(80) \\
6(100) \\
5(100) \\
0 \\
19(90)\end{array}$ & $\begin{array}{r}24 \\
7 \\
8 \\
1 \\
40\end{array}$ & $\begin{array}{r}20(83) \\
7(100) \\
7 \quad(87) \\
1 \quad \\
35 \quad(88)\end{array}$ \\
\hline
\end{tabular}

CABG, coronary artery bypass graft; LAD, left anterior descending; LCX, left circumflex; MVD, multivessel disease; RCA, right coronary artery; SVD, single vessel disease. 

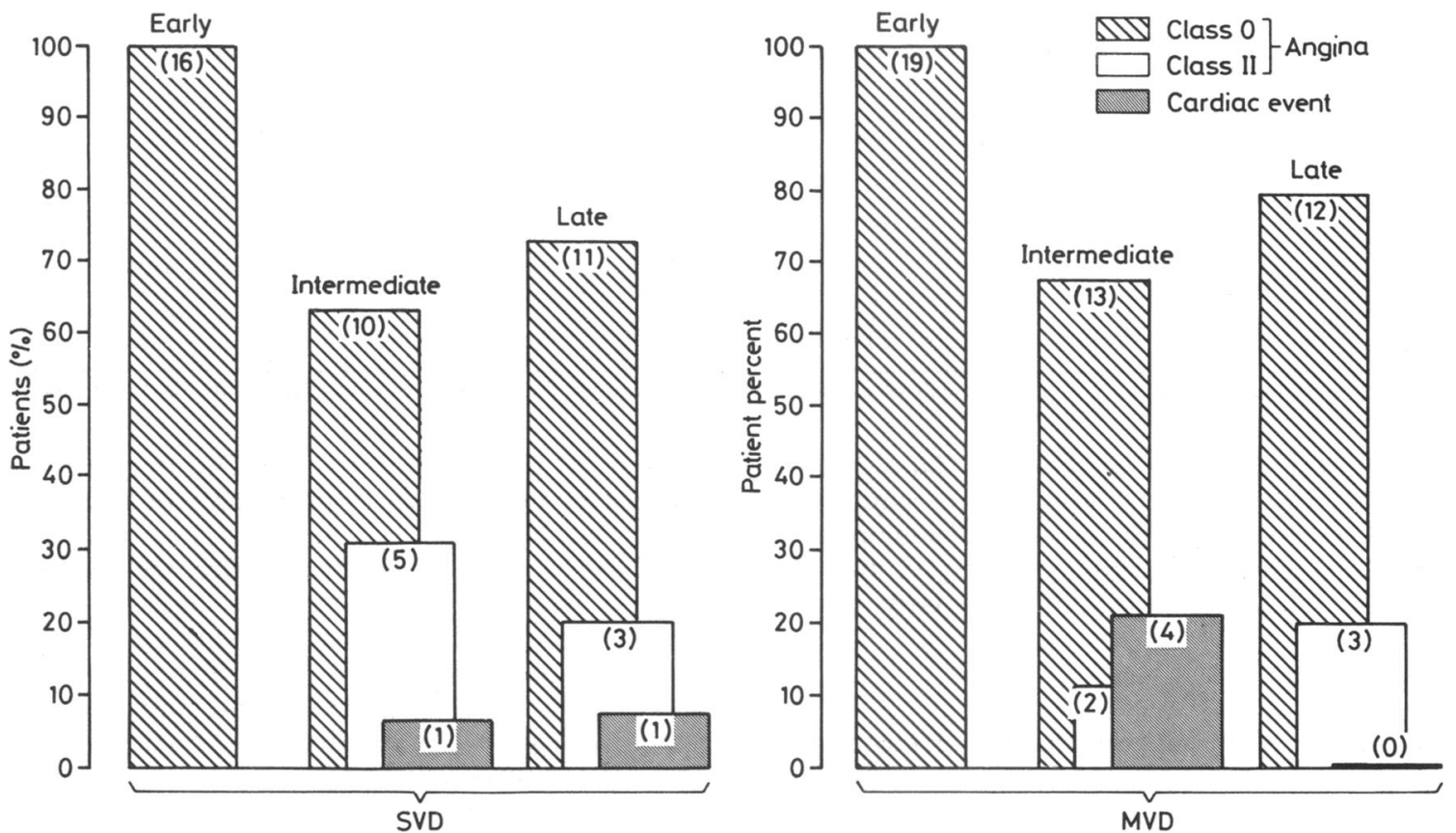

Fig 1 Early, intermediate, and late follow up after successful one vessel percutaneous transluminal coronary angioplasty in patients with unstable angina pectoris that was refractory to medical treatment. The numbers in parentheses indicate the number of patients. The severity of anginal symptoms is classified according to the New York Heart Association classification. Comparisons between patients with single vessel coronary disease (SVD) and multivessel coronary disease (MVD) did not reach statistical significance.

calcium channel blockers or both. All seven patients with symptoms were taking $\beta$ blockers, nitrates, and calcium antagonists. Treadmill stress tests (table 3 ) were performed by $22(63 \%)$ patients and were negative in $14(64 \%)$.

Within the first 12 months two patients had a recurrence of refractory unstable angina. In both patients angiography showed restenosis of the vessel. This cardiac event constituted a failure of treatment and both patients were excluded from further follow up. There were no deaths and no patient sustained a myocardial infarction during this period. Fourteen patients had repeat coronary angiography for class II or III angina and a positive treadmill stress test. In eight patients a restenosis was seen. Two other patients had progression of disease within a vessel in which angioplasty had not previously been attempted. In the remaining four patients there was no change from the post-angioplasty angiogram. Percutaneous transluminal coronary angioplasty was repeated in six of the eight patients with restenosis and was successful in five. One patient had emergency bypass graft surgery. The two patients with progression of disease within an artery not originally treated by angioplasty for refractory unstable angina had successful angioplasty but. were excluded from further follow up. Thus 30 of 35 patients remained in the study at one year.

\section{LATE FOLLOW UP (MEAN 26 MONTHS, RANGE 12} TO 36 MONTHS)

At late follow up in the 30 patients, $23(77 \%)$ were symptom free, six $(20 \%)$ had symptoms, and one had a non-fatal myocardial infarction. Eight of the 23 symptom free patients were not taking an antianginal agent while 15 were taking $\beta$ blockers or calcium channel blockers or both. Of these 15,13 hypertensive patients were continued on $\beta$ blockers or calcium channel blockers or both while two normotensive patients were given prophylactic doses of these drugs. All six patients with symptoms who were taking nitrates and $\beta$ blockers and calcium channel blockers had class II angina. The percentage of patients with symptoms was similar in patients with single vessel disease and multivessel disease (fig 1). Treadmill stress tests (table 3 ) were performed by 24 patients and were negative in $16(67 \%)$. During this late follow up, 12 of the 30 patients had repeat coronary angiography. In three patients, progression of disease was seen within the vessel that had been treated by angioplasty. No patient who had angiography showed progression of disease within a vessel that had not previously been treated by angioplasty. One patient had no change in coronary angiographic anatomy despite chest pain. Percutaneous transluminal coronary angioplasty was successfully repeated in two patients for restenosis, while one 
Table 3 Treadmill stress tests during follow up

\begin{tabular}{|c|c|c|c|c|c|c|c|c|c|}
\hline & \multicolumn{3}{|l|}{ Early } & \multicolumn{3}{|c|}{ Intermediate } & \multicolumn{3}{|l|}{ Late } \\
\hline & $\begin{array}{l}S V D \\
\text { No }(\%)\end{array}$ & $\begin{array}{l}M V D \\
\text { No }(\%)\end{array}$ & $\begin{array}{l}\text { Total } \\
\text { No }(\%)\end{array}$ & $\begin{array}{l}S V D \\
\text { No }(\%)\end{array}$ & $\begin{array}{l}M V D \\
\text { No }(\%)\end{array}$ & $\begin{array}{l}\text { Total } \\
\text { No }(\%)\end{array}$ & $\begin{array}{l}S V D \\
\text { No }(\%)\end{array}$ & $\begin{array}{l}M V D \\
\text { No }(\%)\end{array}$ & $\begin{array}{l}\text { Total } \overline{\mathrm{C}} \\
\text { No } \% \text { 定 }\end{array}$ \\
\hline $\begin{array}{l}\text { Patients } \\
\text { Negative TMST } \\
\text { Positive TMST } \\
\text { Ischaemic changes PTCA area } \\
\text { Exercise duration (minutes) } \\
\text { 85\% PHR }\end{array}$ & $\begin{array}{l}12 \\
10(83) \\
2(17) \\
1(8) \\
7 \\
7(58)\end{array}$ & $\begin{array}{l}16 \\
10(63) \\
6(37) \\
1 \quad(6) \\
6 \\
7(44)\end{array}$ & $\begin{array}{l}28 \\
20(71) \\
8(29) \\
2(7) \\
6 \\
14(50)\end{array}$ & $\begin{array}{l}8 \\
6(75) \\
2(25) \\
2(25) \\
8 \\
7(88)\end{array}$ & $\begin{array}{l}14 \\
8(57) \\
6(43) \\
1(7) \\
6 \\
7(50)\end{array}$ & $\begin{array}{l}22 \\
14(64) \\
8(36) \\
3(14) \\
7 \\
14(64)\end{array}$ & $\begin{array}{l}12 \\
7(58) \\
5(42) \\
4(33) \\
7 \\
7(58)\end{array}$ & $\begin{array}{l}12 \\
9(75) \\
3(25) \\
0 \\
8 \\
7(58)\end{array}$ & 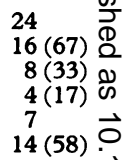 \\
\hline
\end{tabular}

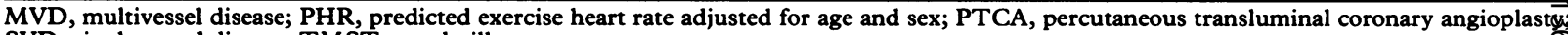
SVD, single vessel disease; TMST, treadmill stress test.

patient declined repeat angioplasty. Thus $29(73 \%)$ of 40 patients had long term symptomatic improvement (fig 2). After successful angioplasty six $(17 \%)$ patients had cardiac events; in five these occurred within six months of angioplasty (fig 3).

\section{Discussion}

The present study suggests that percutaneous transluminal coronary angioplasty of one vessel may be an alternative to coronary artery bypass graft surgery in patients with unstable angina that is refractory to medical treatment. It also shows that selective coronary angiography may be reliable in identifying lesions precipitating refractory unstable angina in patients with multivessel disease. Coronary artery bypass graft surgery has been the only accepted treatment for these patients. De Feyter et al have described the feasibility of percutaneous transluminal coronary angioplasty in this subset of patients as an alternative to coronary artery bypass graft surgery. ${ }^{14}$ Their study indicated that percutaneous transluminal coronary angioplasty relieves symptoms, improves exercise capacity, and reduces the frequency of myocardial infarction and death in the first year in patients who generally had single vessel disease. On the other hand, we studied a population in which half the patients had single vessel disease and half had multivessel coronary arterial disease. We followed them for up to three years after angioplasty. Percutaneous transluminal coronary angioplasty was performed as an emergency procedure in the study of De Feyter et al but not in ours.

The procedural success rate for the current study is similar to that reported for percutaneous transluminal coronary angioplasty in stable angina $a^{178}$ and higher than the $61-76 \%$ success rate reported in earlier studies of patients who generally had single vessel disease and unstable angina. ${ }^{11-13}$ The National Heart, Lung, and Blood Institute reported acute myocardial infarction in $9 \%$ and in-hospital mortality in $0.9 \%$ of patients with unstable angina during percutaneous transluminal coronary angioplasty ${ }^{11}$ while in another study the frequency of emergency coronary artery bypass graft surgery was $7 \%$ with an in-hospital mortality of $1.7 \%{ }^{14}$ The frequency of emergency bypass surgery in the present study was somewhat higher $(12 \%)$ but with no in-hospital mortality and no significant difference between patients with single or multivessel disease. In the early follow up period all patients with either single or multivessel disease in whom angioplasty was successful became symptom free and improved their exercise capacity. During this period no patient died or sustained myocardial infarction.

Late follow up in our study showed that the proportion of patients with symptomatic improve-

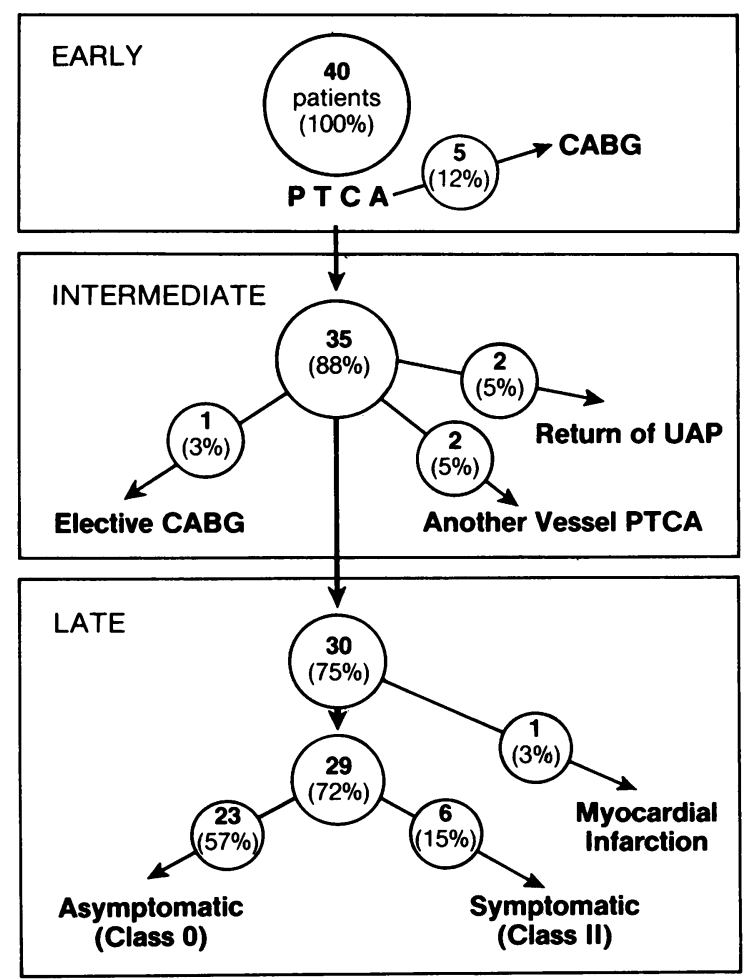

Fig 2 Diagrammatic representation of the course of patients after one vessel percutaneous angioplasty (PTCA) for the relief of refractory unstable angina (UAP). $C A B G$, coronary artery bypass graft surgery. 


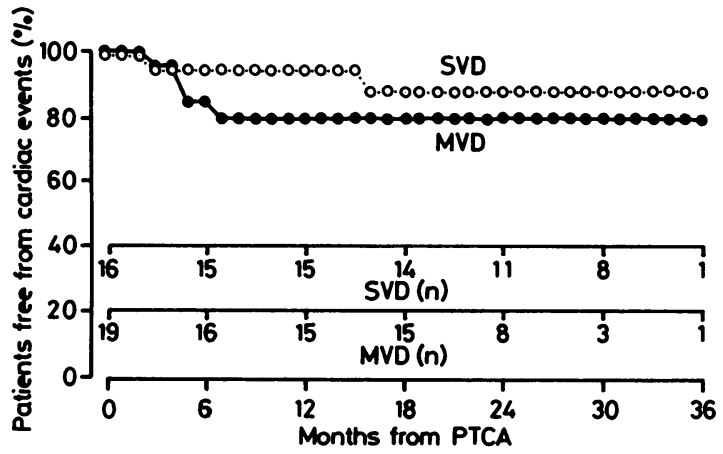

Fig 3 Comparative actuarial analysis of cardiac events in patients with either single vessel coronary artery disease (SVD) or multivessel coronary artery disease (MVD) who had one vessel percutaneous transluminal coronary angioplasty (PTCA) for the relief of refractory unstable angina. The numbers below the abscissa indicate the number of patients being followed. There was no statistical difference in plots comparing patients with single vessel or multivessel disease.

ment was the same in the groups with single vessel disease and multivessel disease. These results are similar to those reported in a study of patients with unstable angina and single vessel disease in which successful percutaneous transluminal coronary angioplasty was successful $(80 \%)$ as bypass surgery in improving symptoms. ${ }^{11}$ None the less, although patients with multivessel disease and one vessel percutaneous transluminal coronary angioplasty are asymptomatic they often have a positive treadmill stress test. This may be attributable to incomplete revascular:sation. Two groups have attempted to produce complete revascularisation in patients with multivessel disease by percutaneous transluminal coronary angioplasty. ${ }^{19}{ }^{20}$ Knudtson et al reported no difference in the clinical course when complete or incomplete revascularisation was achieved by percutaneous transluminal coronary angioplasty in patients with stable angina and multivessel disease. ${ }^{19}$ Similarly, anginal patients with multivessel disease had residual ischaemia during exercise with positive treadmill stress tests after angioplasty. ${ }^{21-24}$

Thus our data suggest that percutaneous transluminal coronary angioplasty of a single critically stenosed artery may be a viable alternative to surgical revascularisation and may be associated with fewer cardiac events than other treatments. ${ }^{2325}$ This was not a randomised study-randomisation would require a single graft to the most stenotic lesion in patients with multivessel disease rather than complete revascularisation-however, it does compare patients with complete revascularisation (single vessel disease and one vessel angioplasty) and those with incomplete revascularisation (multivessel disease and one vessel angioplasty). The results of incomplete and complete revascularisation are similar.

In patients with unstable angina there is a considerable increase in circulating platelet aggregates, ${ }^{26}{ }^{27}$ platelet factor IV, $\beta$ thromboglobulin, and thromboxane $\mathrm{A}_{2}{ }^{28}$ These alterations in platelet homoeostasis strongly suggest that platelets are an important faction within the culprit lesion in the precipitation of unstable angina. Smitherman in his review of unstable angina argues that, based on such evidence, the onset of unstable angina reflects a juncture at which thrombotic events rapidly progress at the site of fixed coronary stenosis to produce dynamic coronary stenosis. ${ }^{29}$ Such thrombi within the culprit lesion have been visualised with angioscopy.$^{30}$ In such a situation anticoagulants may be effective in the management of unstable angina and indeed two large scale multicentre clinical trials have shown that aspirin is effective in treating unstable angina. ${ }^{731}$

Yet there are patients who despite taking maximal tolerated medications, including anticoagulants, remain refractory to medical treatment. In that subpopulation percutaneous transluminal coronary angioplasty may, by reducing the fixed coronary stenosis, prevent the development of the local environment necessary for platelet activation. Nevertheless, as angioplasty may produce iatrogenic trauma within the coronary artery heparin or some other anticoagulant should be given for a short time after angioplasty.

Long term anticoagulation was not attempted in this study. Such treatment may reduce the incidence of restenosis but no placebo controlled studies have yet been reported and published reports are uncertain whether long term anticoagulation significantly alters the prognosis after percutaneous transluminal coronary angioplasty. ${ }^{32}$

In conclusion, the results of the current study indicate that one vessel percutaneous transluminal coronary angioplasty will produce the symptomatic relief of refractory unstable angina pectoris with an improvement in exercise tolerance and a low incidence of cardiac events.

\section{References}

1 Mulcahy R, Awadhi AH, de Buitleor M, Tobin G, Johnson H, Contoy R. Natural history and prognosis of unstable angina. Am Heart J 1985;109:753-8.

2 Unstable angina pectoris. National Cooperative Study Group to compare medical and surgical therapy. II. In-hospital experience and initial follow-up results in patients with one, two and three vessel disease. $A m J$ Cardiol 1978;42:839-48.

3 Bertolasi CA, Tronge JE, Riccitelli MA, Villamayor RM, Zuffardi E. Natural history of unstable angina 
with medical or surgical therapy. Chest 1976;70:596605.

4 Gazes PC, Mobley EM, Faris HM, Duncan RC, Humphries GB. Preinfarctional (unstable) angina: a prospective study at 10 years follow up. Circulation 1973;48:331-6.

5 Mikolich JR, Nicoloff NB, Robinson PH, Logne RB. Relief of refractory angina with continuous infusion of nitroglycerin. Chest 1980;77:375-9.

6 Norris RM, Clarke ED, Samuel NL, Smith WN, Williams B. Protective effect of propranolol in threatened myocardial infarction. Lancet 1978; ii:907-9.

7 Lewis HD, Davis JW, Archibald DG, et al. Protective effects of aspirin against acute myocardial infarction and death in man with unstable angina. Results of a Veterans Administration cooperative study. $N$ Engl J Med 1983;309:396-403.

8 Gerstenblith G, Ohyang P, Achuff SE, et al. Nifedepine in unstable angina: a double blind, randomized trial. N Engl J Med 1982;306:885-9.

9 Theroux P, Taeymans Y, Morissette D, Bosch X, Pallestier GB, Waters DD. A randomized study comparing propranolol and diltiazen in the treatment of unstable angina. J Am Coll Cardiol 1985;5:717-22.

10 Kellett MA, McCabe CH, McCormic JR, Faxon DP, Ryan TJ. The incidence of myocardial infarction or death in patients with unstable angina refractory to maximal medical therapy [Abstract]. Circulation 1983;68(suppl III):256.

11 Faxon DP, Detre KM, McCabe CH, et al. Role of percutaneous transluminal coronary angioplasty in the treatment of unstable angina. Report from the National Heart, Lung and Blood Institute, percutaneous transluminal coronary angioplasty and coronary artery surgery study registries. Am J Cardiol 1983:53-131C-5C.

12 Williams DO, Riley RS, Singh AK, Gewirtz H, Most AS. Evaluation of the role of coronary angioplasty in patients with unstable angina pectoris. Am Heart J 1981;102:1-9.

13 Meyer J, Schimtz H, Erbel R, et al. Treatment of unstable angina pectoris with percutaneous transluminal coronary angioplasty (PTCA). Cathet Cardiovasc Diagn 1981;7:361-71.

14 De Feyter PJ, Serruys PW, Van Den Brand M, et al. Emergency coronary angioplasty in refractory unstable angina. N Engl J Med 1985;313:342-6.

15 Rahimtoola SH, Nunley D, Grunkemeier G, Tepley J, Lambert L, Starr A. Ten-year survival after coronary bypass surgery for unstable angina. $N$ Engl $J$ Med 1983;308:676-81.

16 Grüntzig AR, Senning A, Siegenthaler WE. Nonoperative dilatation of coronary-artery stenosis. Percutaneous transluminal coronary angioplasty. N Engl J Med 1979;301:61-8.

17 Cowley MJ, Block PC. Percutaneous transluminal angioplasty. Mod Concepts Cardiovasc Dis 1981; 50:25-9.

18 Meier B, Grüntzig AR, King SB, et al. Higher balloon dilatation pressure in coronary angioplasty. Am Heart $J$ 1984;107:619-22.

19 Knudtson ML, Hansen JL, Manyari DL, Roth DL, Flintoft VF. The role of incomplete revascularization by PTCA in patients with multivessel coronary artery disease [Abstract]. Circulation 1984;70(suppl II):108.

20 Myler RK, Cote G, Topol EJ, Stertzer SH, Fishman-Rosen JF, Murphy MC. Considerations in angioplasty and laser ablation; multiple vessel angioplasty: definition, classification, and results [Abstract]. J Am Coll Cardiol 1986;7:237A.

21 Kloster FE, Kremkau EL, Ritzmann LW, Rahimtoola SH, Rosch J, Kanarek PH. Coronary bypass for stable angina. A prospective randomized study. N Engl J Med 1979;300:149-57.

22 Berger BC, Watson DD, Burwell LR, et al. Redistribution of thallium at rest in patients with stable and unstable angina and the effect of coronary artery bypass surgery. Circulation 1979;60:1114-25.

23 Kent KM, Borer JS, Green MV, et al. Effects of coronary-artery bypass on global and regional left ventricular function during exercise. $N$ Engl $J$ Med 1978;298:1434-9.

24 Wei-I L, Riggins RCK, Anderson RP. Reversal of exertional hypotension after coronary bypass grafting. Am J Cardiol 1979;44:607-11.

25 Rahimtoola SH. Postoperative exercise response in the evaluation of the physiologic status after coronary bypass surgery. Circulation 1982;65(suppl II): 106-14.

26 Schwartz MB, Hawiger J, Timmons S, Friesinger GC Platelet aggregates in ischemic heart disease. Thromb Haemost 1980;43:185-8.

27 Neri Serneri GG, Gensini GF, Abbate R, et al. Increased fibrinopeptide $A$ formation and thromboxane A2 production in patients with ischemic heart disease: relationship to coronary pathoanatomy, risk factors, and clinical manifestations. Am Heart J 1981; 101:185-94.

28 Hirsh PD, Hillis LD, Cambell WB, Fieth BG, Willerson JT. Release of prostaglandins and thromboxane into the coronary circulation in patients with ischemic heart disease. $N$ Engl J Med 1981;304: 685-91.

29 Smitherman TC. Southwestern internal medicine conference: unstable angina pectoris: the first half century: natural history, pathophysiology, and treatment. Am J Med Sci 1986;292:395-406.

30 Sherman CT, Litvack F, Grundfest W, et al. Coronary angioscopy in patients with unstable angina pectoris. $N$ Engl J Med 1986;315:913-9.

31 Cairns JA, Gent M, Singer J, et al. Aspirin sulfinpyrazole or both in unstable angina: results of a Canadian multicenter trial. N Engl J Med 0 1985;313:1369-75.

32 Lopez LM, Mehta JL. Anticoagulation in coronary $\stackrel{?}{?}$ heart disease: Heparin and warfarin trials. In: Mehta 0 $\mathrm{JL}$, ed. Thrombosis and platelets in myocardial $\mathrm{O}$ ischemia. Philadelphia: FA Davis, 1987:215-29. त̄ (Brest AN, ed. Cardiovascular clinics; vol 18; No 1.) 